\title{
Body Influences on Social Cognition Through Interoception
}

\author{
Qiyang Gao ${ }^{1,2}$, Xianjie Ping $^{2}$ and Wei Chen ${ }^{1,2,3 *}$ \\ ${ }^{1}$ Department of Psychology, Shaoxing University, Shaoxing, China, ${ }^{2}$ Center for Brain, Mind and Education, Shaoxing \\ University, Shaoxing, China, ${ }^{3}$ Interdisciplinary Center for Philosophy and Cognitive Sciences, Renmin University of China, \\ Beijing, China
}

Keywords: interoception, social cognition, visceroception, proprioception, body

\section{INTRODUCTION}

From the dichotomy of body and mind to embodied cognition, the body as a material entity has become increasingly important in the cognitive development of individuals. Embodied cognition strengthens the current view that the body plays an essential role in cognition. For example, regarding the influence of body anatomy on cognition, if we replace human eyes with a bat's echolocation system, we will perceive the world in a completely different way (Goldman and de Vignemont, 2009). The impact of bodily activity on cognition is illustrated by better word memory and mathematical problem solving resulting from the use of hand gestures (Macedonia, 2014; Cook et al., 2017). The influence of bodily content and bodily format on cognition is shown when participants who reviewed resumes with heavy clipboards rather than light clipboards believed a candidate was more serious and had a better overall evaluation of that candidate (Ackerman et al., 2010). Regrettably, these studies focus on the causal effects of the body on cognition and ignore the influence of the internal state of the body on cognitive processing. Body ownership is a

\section{OPEN ACCESS}

Edited by:

Varun Dutt,

Indian Institute of Technology

Mandi, India

Reviewed by:

Palvi Agganwal,

Carnegie Mellon University,

United States

*Correspondence:

Wei Chen

anti-monist@163.com

Specialty section:

This article was submitted to

Cognitive Science,

a section of the journal

Frontiers in Psychology

Received: 21 April 2019

Accepted: 26 August 2019

Published: 10 September 2019

Citation:

Gao Q, Ping X and Chen W (2019)

Body Influences on Social Cognition

Through Interoception.

Front. Psychol. 10:2066.

doi: 10.3389/fpsyg.2019.02066 fundamental dimension of the bodily self which refers to the feeling that my body belongs to me, and the experience of body ownership is moderated by interindividual differences in the sensitivity to stimuli originating inside of the body, that is, by interoception (Schauder et al., 2015; Chen et al., 2017). It has been proposed that interoception also can moderate embodiments (Häfner, 2013). Interoception refers to the perception of internal body states; it is the intermediary between body and cognition. Several studies have demonstrated that interoception plays an important role in implicit memory processes and intuitive decision making (Dunn et al., 2010; Werner et al., 2010). Therefore, an "embodied sense of self" or "sense of embodiment" can become a new indicator of embodied cognition (Kilteni et al., 2012).

Social cognition is "a sub-topic of social psychology that focuses on how people process, store, and apply information about other people and social situations. It focuses on the role that cognitive processes play in social interactions" (Park et al., 2015). To date, an embodiment perspective has motivated novel insights about the understanding of others' minds (Wilson and Foglia, 2017), but how the body affects social cognition is still unclear. In this paper, we provide evidence that the body influences one's social cognition through interoception.

Interoception, as first proposed by Sherrington in 1906, originally only was referred to as visceroception (such as heart rate, breath, and hunger, etc.), and it did not include organs like the brain and skin (Tsakiris, 2017). It now refers to the ability to detect the feelings of internal bodily sensations, including proprioception (signals from the skin and musculoskeletal apparatus) and visceroception (Herbert and Pollatos, 2012; Schauder et al., 2015; Pollatos et al., 2016). Activation of interoceptive representations and meta-representations of bodily signals supporting interoceptive awareness are closely related to emotional experience and cognitive functions (Herbert and Pollatos, 2012). In this paper, we first explore interoception in general, review studies about proprioception and visceroception, and discuss the related brain regions. Thereafter, we summarize the relevant studies showing the association of social cognition with interoception in Table 1. Since the core components of social cognition are still the subject of some debate, we focus here on the 
TABLE 1 | Relevant studies showing the association of social cognition with interoception.

\begin{tabular}{|c|c|c|c|c|}
\hline Study & Participants & Instruments/methods & Main findings & $\begin{array}{l}\text { Attributies/neural } \\
\text { correlates of social } \\
\text { cognition }\end{array}$ \\
\hline Shah et al. (2017) & 72 healthy adults & $\begin{array}{l}\text { MASC, the heartbeat tracking } \\
\text { task }\end{array}$ & $\begin{array}{l}\text { Visceroception plays an important } \\
\text { role in understanding emotion. }\end{array}$ & ToM \\
\hline Fukushima et al. (2011) & $\begin{array}{l}21 \text { healthy undergraduate } \\
\text { students }\end{array}$ & $\begin{array}{l}\text { EEG, ECG, the affective-judgment } \\
\text { task, and the physical-judgment } \\
\text { task }\end{array}$ & $\begin{array}{l}\text { Visceroception may contribute to } \\
\text { inferring the affective state of } \\
\text { others. }\end{array}$ & Empathy \\
\hline Grynberg and Pollatos (2015) & $\begin{array}{l}93 \text { healthy undergraduate } \\
\text { students }\end{array}$ & $\begin{array}{l}\text { The Self-Assessment Manikin, the } \\
\text { heartbeat perception task }\end{array}$ & $\begin{array}{l}\text { Visceroception can shape both } \\
\text { affective and cognitive empathy. }\end{array}$ & Empathy \\
\hline Terasawa et al. (2014) & $\begin{array}{l}30 \text { healthy undergraduate and } \\
\text { graduate students }\end{array}$ & $\begin{array}{l}\text { The heartbeat detection task and } \\
\text { the emotional sensitivity task }\end{array}$ & $\begin{array}{l}\text { Visceroception modulates the } \\
\text { intensity of the emotional } \\
\text { experience. }\end{array}$ & Empathy \\
\hline Ernst et al. (2013) & 18 healthy adults & $\begin{array}{l}\mathrm{fMRI} \text {, the empathy task, and the } \\
\text { interoceptive task }\end{array}$ & $\begin{array}{l}\text { The preceding visceral sensory } \\
\text { awareness enhances neural } \\
\text { activity in bilateral insula and } \\
\text { various midline regions during } \\
\text { empathy. }\end{array}$ & Empathy \\
\hline Sedeño et al. (2014) & $\begin{array}{l}\mathrm{JM} \text {, a male patient with } \\
\text { Depersonalization-Derealization } \\
\text { Disorder and } 10 \text { age-matched } \\
\text { healthy male }\end{array}$ & $\begin{array}{l}\mathrm{fMRI} \text {, the heartbeat detection } \\
\text { task, and the empathy tasks }\end{array}$ & $\begin{array}{l}\text { The impairments in the perception } \\
\text { and integration of visceral } \\
\text { information might lead to } \\
\text { disruptions in affective empathic } \\
\text { response. }\end{array}$ & Empathy \\
\hline Haswell et al. (2009) & $\begin{array}{l}14 \text { ASD children and } 13 \text { typically } \\
\text { developing children }\end{array}$ & A motor task & $\begin{array}{l}\text { The higher dependence on } \\
\text { proprioception predicts the } \\
\text { greater impairments in imitation. }\end{array}$ & Imitation \\
\hline Izawa et al. (2012) & $\begin{array}{l}23 \text { ASD children, } 17 \text { ADHD } \\
\text { children, and } 20 \text { typically } \\
\text { developing children }\end{array}$ & A motor task & $\begin{array}{l}\text { Dependence on proprioception } \\
\text { leads to impaired ability to imitate. }\end{array}$ & Imitation \\
\hline Greenfield et al. (2015) & $\begin{array}{l}31 \text { ASD children, } 29 \\
\text { chronological age-matched } \\
\text { children, and } 29 \text { verbal } \\
\text { mental-age-matched children }\end{array}$ & A MIRAGE task & $\begin{array}{l}\text { A greater reliance on } \\
\text { proprioception would impact on } \\
\text { sensitivity to social processes } \\
\text { such as empathy and imitation. }\end{array}$ & Empathy and imitation \\
\hline Tsakiris et al. (2006) & 15 healthy adults & PET, the rubber hand illusion task & $\begin{array}{l}\text { The proprioceptive behavioral } \\
\text { data is positively correlated with } \\
\text { activity in the right posterior insula } \\
\text { and right frontal operculum. }\end{array}$ & $\begin{array}{l}\text { Empathy/the anterior insula, } \\
\text { the anterior cingulate cortex, } \\
\text { and the midcingulate cortex. }\end{array}$ \\
\hline Critchley et al. (2004) & 17 healthy subjects & fMRI, the heartbeat detection task & $\begin{array}{l}\text { The right anterior insula supports } \\
\text { a representation of visceral } \\
\text { responses. }\end{array}$ & $\begin{array}{l}\text { Empathy/the anterior insula, } \\
\text { the anterior cingulate cortex, } \\
\text { and the midcingulate cortex. }\end{array}$ \\
\hline Ronchi et al. (2015) & $\begin{array}{l}\text { A patient with injured right insula } \\
\text { and } 16 \text { age-matched healthy } \\
\text { subjects }\end{array}$ & ECG, the heartbeat detection task & $\begin{array}{l}\text { The insula plays a key role in } \\
\text { interoceptive-cardiac processing. }\end{array}$ & $\begin{array}{l}\text { Empathy/the anterior insula, } \\
\text { the anterior cingulate cortex, } \\
\text { and the midcingulate cortex. }\end{array}$ \\
\hline
\end{tabular}

traditionally associated processes: theory of mind (ToM), empathy, and imitation (Happé et al., 2017). Finally, we suggest that improving the sensitivity or accuracy of interoception can enhance one's ability to understand the mental state of others, thereby enabling better social communication.

\section{VISCEROCEPTION AND SOCIAL COGNITION}

Visceroception is the perception of internal body signals. These signals are mainly generated in four systems: cardiovascular, respiratory, gastrointestinal, and urogenital (mainly corresponding to the heart, lungs, stomach, and bladder) as well as other internal organs in the body torso. Among these, the cardiovascular system is the focus of research (Tsakiris, 2017), and perceived heartbeat is the most important experimental measure of interoception (Häfner, 2013; Melloni et al., 2013). The interoception in these cases essentially refers to visceroception.

Theory of Mind (ToM), an important aspect of social cognition, refers to the everyday ability to attribute independent mental states to oneself and others in order to predict and explain behavior (Premack and Woodruff, 1978; Shah et al., 2017). Shah et al. (2017) investigated whether visceroception can predict the mental states or only play an important role in understanding emotion. In the experiment, the participants focused their attention by silently counting their heartbeats 
during intervals of varying duration and then completed a questionnaire [the Movie for the Assessment of Social Cognition (MASC)] on ToM. The results showed that there was a positive correlation between interoceptive accuracy and overall MASC score. However, interoception is not necessary for the representation of mental states. It helps to accurately represent mental states in situations where the process is reliant on emotional or otherwise interoceptive information. That is, visceroception may be more relevant to the emotional aspects of social cognition.

Empathy-the understanding of the affective states of others (Fukushima et al., 2011) - is also an aspect of social cognition and plays a vital role in daily social activities. Fukushima et al. (2011) used the heartbeat-evoked potential (HEP) as a neural index of visceroception processing. Participants performed empathy tasks while electroencephalography (EEG) and electrocardiogram (ECG) measurements were recorded. The results showed that afferent feedback from visceral activity may contribute to inferring the affective state of others. Another study used a heartbeat perception task to prove that visceral sensitivity can shape both affective and cognitive empathy. Grynberg and Pollatos (2015) observed that participants with greater visceroception sensitivity overestimated the degree of pain (cognitive empathy), as well as arousal and feelings of compassion (affective empathy) when they saw pictures depicting other people in pain.

In neurophysiology, studies have shown that the anterior insula, the anterior cingulate cortex, and the midcingulate cortex are associated with empathy, and the insular cortex is also associated with the affective processing of self and others, and a wide range of social cognition processes (Bernhardt and Singer, 2012). The insula is also the central interoceptive hub in the brain (Craig and Craig, 2009). Ronchi et al. (2015) reported a single-case study showing that heartbeat awareness decreased after insular resection. In addition, Critchley et al. (2004) used functional magnetic resonance imaging (fMRI) and found that the activity of the insula, somatomotor cortex, and cingulate cortex was enhanced during the heartbeat perception task. Taken together, the overlap between the brain area related to visceroception and empathy further highlights visceroception as an important role for social cognition.

\section{PROPRIOCEPTION AND SOCIAL COGNITION}

The term "proprioception" was introduced by Sherrington (1906) as the function of providing information about limb position and movement and, through the vestibular system, about balance and related whole-body properties (Gallagher, 2011).

Proprioception is closely related to the understanding of the intentions and beliefs of others. The account of the physician and philosopher Thomas Fuchs highlights the role of proprioception as a resource of understanding others. In his opinion, the proprioceptive skills of a physician can support the empathic understanding of the physician (Schmidsberger and Löffler-Stastka, 2018).
In addition, proprioception also has a regulating effect on imitation, an important aspect of social cognition. Proprioception normally promotes the development of social cognition, however patients with autism spectrum disorder (ASD) show the opposite situation. ASD children not only have defects in the development of social skills, but also have defects in the development of motor skills. In a study in which children learned to control a robotic arm to reach toward a target, Haswell et al. (2009) found that children with ASD placed a greater reliance on proprioception alone, and the internal models that they form place a stronger than normal association between the self-generated motor commands and proprioception, which indicates that sports, imitation, and social skills are compromised. As such, the higher dependence on proprioception, the more serious damage to social function and imitation. The same results have also been recognized by other researchers (Izawa et al., 2012).

Evidence indicates that social functioning deficits of children with ASD may be related to an over-reliance on proprioception or atypical visuo-tactile temporal binding (Cascio et al., 2012). It has been shown that ASD patients do have temporally extended visuo-tactile binding, which may result in reduced processing of temporal synchrony inputs over proprioception. This would likely lead to failures in appropriately binding information from related events, which would in turn impact sensitivity to social processes such as empathy and imitation (Greenfield et al., 2015).

Quattrocki and Friston (2014) gave another explanation for the abnormal behavior of ASD, suggesting that autism is caused by a dysfunctional oxytocin system in early life. Oxytocin has specific and targeted effects on the medial prefrontal cortex, the insula, the anterior cingulate, and the inferior frontal gyrus (Ninan, 2011; Riem et al., 2011). The distribution of oxytocin receptor in the brain supports the role of oxytocin in the transmission and modulation of interoceptive signals (prediction errors) in neuronal circuits. Oxytocin can inhibit the interoceptive signal and play an important role in the attenuation of it. The attenuation of interoceptive sensing may also be a necessary condition for the emergence of cognitive empathy and compassionate behavior. In addition, clinical studies have suggested that exogenous oxytocin improved empathy and the ability to infer the mindset of others (Bartz et al., 2010), demonstrating the important impact of interoception on social cognition.

\section{CONCLUSION}

Interoception refers to the perception of internal body states, playing an important role in the mental representation of the self. Self-representation is indispensable for a wide range of social cognition processes. In this paper, we demonstrated that interoception can influence social cognition, that is, the body can influence the individual's social cognition through interoception.

Specifically, improving one's interoceptive sensitivity or interoceptive accuracy can improve one's social cognition. Studies have shown that a tendency to focus on one's own internal experiences, or to conduct experimental self-observation, such as 
looking at oneself in a mirror and gazing at a self-photograph and at self-relevant words, can improve the accuracy of heartbeat perception (Ainley et al., 2012). Combined with the viewpoint of this paper, the above method can improve one's interoceptive sensitivity and improve social cognition accordingly.

Children are developing individuals, and their social cognition has a high degree of plasticity (Frick et al., 2014). It is more convenient to improve children's social cognition through interoception, and it may achieve good practical results. Future research can start from this aspect, recruiting participants of the corresponding age stage to test the validity of this view.

\section{AUTHOR CONTRIBUTIONS}

All authors listed have made a substantial, direct and intellectual contribution to the work, and approved it for publication.

\section{REFERENCES}

Ackerman, J. M., Nocera, C. C., and Bargh, J. A. (2010). Incidental haptic sensations influence social judgments and decisions. Science 328, 1712-1715. doi: $10.1126 /$ science.1189993

Ainley, V., Tajadura-Jiménez, A., Fotopoulou, A., and Tsakiris, M. (2012). Looking into myself: changes in interoceptive sensitivity during mirror self-observation. Psychophysiology 49, 1504-1508. doi: 10.1111/j.1469-8986.2012.01468.x

Bartz, J. A., Zaki, J., Bolger, N., Hollander, E., Ludwig, N. N., Kolevzon, A., et al. (2010). Oxytocin selectively improves empathic accuracy. Psychol. Sci. 21, 1426-1428. doi: 10.1177/0956797610383439

Bernhardt, B. C., and Singer, T. (2012). The neural basis of empathy. Annu. Rev. Neurosci. 35, 1-23. doi: 10.1146/annurev-neuro-062111-150536

Cascio, C. J., Foss-Feig, J. H., Burnette, C. P., Heacock, J. L., and Cosby, A. A. (2012). The rubber hand illusion in children with autism spectrum disorders: delayed influence of combined tactile and visual input on proprioception. Autism 16, 406-419. doi: 10.1177/1362361311430404

Chen, W., Zhang, J., Qian, Y., and Gao, Q. (2017). How disentangled sense of agency and sense of ownership can interact with different emotional events on stress feelings. Psicol. Reflex. Crít. 30:17. doi: 10.1186/s41155-017-0071-y

Cook, S. W., Friedman, H. S., Duggan, K. A., Cui, J., and Popescu, V. (2017). Hand gesture and mathematics learning: lessons from an Avatar. Cogn. Sci. 41, 518-535. doi: 10.1111/cogs. 12344

Craig, A. D., and Craig, A. (2009). How do you feel-now? The anterior insula and human awareness. Nat. Rev. Neurosci. 10, 59-70. doi: 10.1038/nrn2555

Critchley, H. D., Wiens, S., Rotshtein, P., Ohman, A., and Dolan, R. J. (2004). Neural systems supporting interoceptive awareness. Nat. Neurosci. 7, 189-195. doi: $10.1038 / \mathrm{nn} 1176$

Dunn, B. D., Galton, H. C., Morgan, R., Evans, D., Oliver, C., Meyer, M., et al. (2010). Listening to your heart: how interoception shapes emotion experience and intuitive decision making. Psychol. Sci. 21, 1835-1844. doi: $10.1177 / 0956797610389191$

Ernst, J., Northoff, G., Boker, H., Seifritz, E., and Grimm, S. (2013). Interoceptive awareness enhances neural activity during empathy. Hum. Brain Mapp. 34, 1615-1624. doi: 10.1002/hbm.22014

Frick, A., Mohring, W., and Newcombe, N. S. (2014). Picturing perspectives: development of perspective-taking abilities in 4- to 8-year-olds. Front. Psychol. 5:386. doi: 10.3389/fpsyg.2014.00386

Fukushima, H., Terasawa, Y., and Umeda, S. (2011). Association between interoception and empathy: evidence from heartbeat-evoked brain potential. Int. J. Psychophysiol. 79, 259-265. doi: 10.1016/j.ijpsycho.2010.10.015

Gallagher, S. (2011). The Oxford Handbook of the Self. New York, NY: Oxford University Press.

Goldman, A., and de Vignemont, F. (2009). Is social cognition embodied? Trends Cogn. Sci. 13, 154-159. doi: 10.1016/j.tics.2009. 01.007

\section{FUNDING}

This work was supported by the Philosophy and Social Science Foundation of Zhejiang Province (No. 18NDJC112YB), The National Social Science Foundation (No. 16CZX015), Project of the Humanities and Social Science Research of the Ministry of Education of China (No. 17YJC880111). The funding agency had no involvement in the study design, the collection, analysis and interpretation of data, the writing of the report, and nor in the decision to submit the article for publication.

\section{ACKNOWLEDGMENTS}

We would like to thank three reviewers for their helpful comments on this manuscript.

Greenfield, K., Ropar, D., Smith, A. D., Carey, M., and Newport, R. (2015). Visuo-tactile integration in autism: atypical temporal binding may underlie greater reliance on proprioceptive information. Mol. Autism 6:51. doi: 10.1186/s13229-015-0045-9

Grynberg, D., and Pollatos, O. (2015). Perceiving one's body shapes empathy. Physiol. Behav. 140, 54-60. doi: 10.1016/j.physbeh.2014.12.026

Häfner, M. (2013). When body and mind are talking: interoception moderates embodied cognition. Exp. Psychol. 60, 255-259. doi: 10.1027/1618-3169/a000194

Happé, F., Cook, J. L., and Bird, G. (2017). The structure of social cognition: in (ter) dependence of sociocognitive processes. Annu. Rev. Psychol. 68, 243-267. doi: 10.1146/annurev-psych-010416-044046

Haswell, C. C., Izawa, J., Dowell, L. R., Mostofsky, S. H., and Shadmehr, R. (2009). Representation of internal models of action in the autistic brain. Nat. Neurosci. 12, 970-972. doi: 10.1038/nn.2356

Herbert, B. M., and Pollatos, O. (2012). The body in the mind: on the relationship between interoception and embodiment. Top. Cogn. Sci. 4, 692-704. doi: 10.1111/j.1756-8765.2012.01189.x

Izawa, J., Pekny, S. E., Marko, M. K., Haswell, C. C., Shadmehr, R., and Mostofsky, S. H. (2012). Motor learning relies on integrated sensory inputs in ADHD, but over-selectively on proprioception in autism spectrum conditions. Autism Res. 5, 124-136. doi: 10.1002/aur.1222

Kilteni, K., Groten, R., and Slater, M. (2012). The sense of embodiment in virtual reality. Presence Teleop. Virt. 21, 373-387. doi: 10.1162/PRES_a_00124

Macedonia, M. (2014). Bringing back the body into the mind: gestures enhance word learning in foreign language. Front. Psychol. 5:1467. doi: $10.3389 /$ fpsyg.2014.01467

Melloni, M., Sedeño, L., Couto, B., Reynoso, M., Gelormini, C., Favaloro, R., et al. (2013). Preliminary evidence about the effects of meditation on interoceptive sensitivity and social cognition. Behav. Brain Funct. 9:47. doi: 10.1186/1744-9081-9-47

Ninan, I. (2011). Oxytocin suppresses basal glutamatergic transmission but facilitates activity-dependent synaptic potentiation in the medial prefrontal cortex. J. Neurochem. 119, 324-331. doi: 10.1111/j.1471-4159.2011.07430.x

Park, M., Song, J.-J., Oh, S. J., Shin, M.-S., Lee, J. H., and Oh, S. H. (2015). The relation between nonverbal IQ and postoperative CI outcomes in cochlear implant users: preliminary result. Biomed Res. Int. 2015, 1-7. doi: $10.1155 / 2015 / 313274$

Pollatos, O., Herbert, B. M., Berberich, G., Zaudig, M., Krauseneck, T., and Tsakiris, M. (2016). Atypical self-focus effect on interoceptive accuracy in anorexia nervosa. Front. Hum. Neurosci. 10:484. doi: 10.3389/fnhum.2016.00484

Premack, D., and Woodruff, G. (1978). Does the chimpanzee have a theory of mind? Behav. Brain Sci. 1, 515-526. doi: 10.1017/S0140525X00076512

Quattrocki, E., and Friston, K. (2014). Autism, oxytocin and interoception. Neurosci. Biobehav. Rev. 47, 410-430. doi: 10.1016/j.neubiorev.2014.09.012 
Riem, M. M., Bakermans-Kranenburg, M. J., Pieper, S., Tops, M., Boksem, M. A., Vermeiren, R. R., et al. (2011). Oxytocin modulates amygdala, insula, and inferior frontal gyrus responses to infant crying: a randomized controlled trial. Biol. Psychiatry 70, 291-297. doi: 10.1016/j.biopsych.2011.02.006

Ronchi, R., Bello-Ruiz, J., Lukowska, M., Herbelin, B., Cabrilo, I., Schaller, K., et al. (2015). Right insular damage decreases heartbeat awareness and alters cardio-visual effects on bodily self-consciousness. Neuropsychologia 70, 11-20. doi: 10.1016/j.neuropsychologia.2015.02.010

Schauder, K. B., Mash, L. E., Bryant, L. K., and Cascio, C. J. (2015). Interoceptive ability and body awareness in autism spectrum disorder. J. Exp. Child Psychol. 131, 193-200. doi: 10.1016/j.jecp.2014.11.002

Schmidsberger, F., and Löffler-Stastka, H. (2018). Empathy is proprioceptive: the bodily fundament of empathy-a philosophical contribution to medical education. BMC Med. Educ. 18:69. doi: 10.1186/s12909-018-1161-y

Sedeño, L., Couto, B., Melloni, M., Canales-Johnson, A., Yoris, A., Baez, S., et al. (2014). How do you feel when you can't feel your body? Interoception, functional connectivity and emotional processing in depersonalizationderealization disorder. PLoS ONE 9:e98769. doi: 10.1371/journal.pone.0098769

Shah, P., Catmur, C., and Bird, G. (2017). From heart to mind: linking interoception, emotion, and theory of mind. Cortex 93, 220-223. doi: 10.1016/j.cortex.2017.02.010

Sherrington, C. S. (1906). The Integrative Action of the Nervous System. New Haven, CT: Yale University Press.

Terasawa, Y., Moriguchi, Y., Tochizawa, S., and Umeda, S. (2014). Interoceptive sensitivity predicts sensitivity to the emotions of others. Cogn. Emot. 28, 1435-1448. doi: 10.1080/02699931.2014. 888988

Tsakiris, M. (2017). The multisensory basis of the self: from body to identity to others. Q. J. Exp. Psychol. 70, 597-609. doi: 10.1080/17470218.2016.1181768

Tsakiris, M., Hesse, M. D., Boy, C., Haggard, P., and Fink, G. R. (2006). Neural signatures of body ownership: a sensory network for bodily self-consciousness. Cereb. Cortex 17, 2235-2244. doi: 10.1093/cercor/bhl131

Werner, N. S., Peres, I., Duschek, S., and Schandry, R. (2010). Implicit memory for emotional words is modulated by cardiac perception. Biol. Psychol. 85, 370-376. doi: 10.1016/j.biopsycho.2010.08.008

Wilson, R. A., and Foglia, L. (2017). Embodied Cognition. Stanford University: The Stanford Encyclopedia of Philosophy: Metaphysics Research Lab. Available online at: https://plato.stanford.edu/archives/spr2017/entries/embodiedcognition/ (accessed January 3, 2019).

Conflict of Interest Statement: The authors declare that the research was conducted in the absence of any commercial or financial relationships that could be construed as a potential conflict of interest.

Copyright (C) 2019 Gao, Ping and Chen. This is an open-access article distributed under the terms of the Creative Commons Attribution License (CC BY). The use, distribution or reproduction in other forums is permitted, provided the original author(s) and the copyright owner(s) are credited and that the original publication in this journal is cited, in accordance with accepted academic practice. No use, distribution or reproduction is permitted which does not comply with these terms. 